\title{
Closing and Opening of Gap Junction Pores Between Two- and Threedimensionally Cultured Tumor Cells*
}

\author{
D. F. Hülser and F. Brümmer \\ Abteilung Biophysik, Biologisches Institut, Universität Stuttgart, \\ Ulmer Straße 227, D-7000 Stuttgart 60, Federal Republic of Germany
}

\begin{abstract}
Intercellular signal transfer via gap junction pores in cultured multicell spheroids of BICR/M1R-K cells decreases with increasing spheroid age. In two days old spheroids the pores allow passage of Lucifer yellow molecules. Two days later, this fluorescent dye is retained in the injected cell even though the cells are still electrically coupled. Gap junction plaques of considerable size are still found in 9 days old spheroids, when the cells are completely uncoupled. The same cells growing as monolayer cultures do not exhibit such a gradual closing of their gap junction pores: Their coupling is established at first cell contact, probably by a gradual opening of the pores, which remain open even up to 9 days in culture.
\end{abstract}

Key words: Intercellular communication - Gap junctions - Spheroids

\section{Introduction}

Cells of organs and tissues are often linked by gap junction pores. In the case of mammalian cells the pore diameter is about $1.4 \mathrm{~nm}$ (Loewenstein 1979) and enables an intercellular signal transfer with molecules up to a molecular weight of 900 d (Flagg-Newton et al. 1979). Neither the nature of the transmitted message nor its carrier has been identified, however, several possible mechanisms are described, e.g., a gradient of morphogenetic substances (Schaller and Bodenmüller 1981) or oscillating electrical signals (Hülser and Lauterwasser 1982). The regulation of growth and differentiation during embryogenesis is associated with variations of the gap junction permeability and structure as already demonstrated in mammals (Lo and Gilula 1979a and b), amphibians (Ito and Ikematsu 1980; Bennett et al. 1981), and insects (Weir and Lo 1982).

It is questionable whether an endogenous regulation of the gap junction permeability is active in two-dimensionally growing cell monolayers in culture.

\footnotetext{
* Based on material presented at the Symposium "Intercellular Communication" Stuttgart, September $16-17,1982$
} 
A coupling competent cell culture develops gap junctions shortly after the first cell contact and remains in this coupled state within a wide range of temperature and $\mathrm{pH}$, whereas coupling incompetent cell cultures remain in their uncoupled state (Hülser and Webb 1973). We now present evidence that, as for cells during embryogenesis, a regulatory function of gap junctions is established when coupling competent cells are allowed to form three-dimensional multicell spheroids.

\section{Materials and Methods}

\section{Cell Cultures}

BICR/M1R-K cells, a strain originating from a transplantable mammary tumor of the Marshall rat, were cultured at $37^{\circ} \mathrm{C}$ in a modified (Frank et al. 1972) Eagle-Dulbecco medium with 5\% calf serum. Monolayer cultures in plastic petri dishes (Greiner) were regulated at $\mathrm{pH} 7.2$ with an atmosphere of $5 \% \mathrm{CO}_{2}$ in air. Spheroid cultures in glass spinner flasks on magnetic stirrers were agitated by 180 rotations/min in a HEPES-buffered $(30 \mathrm{mM})$ modified Eagle-Dulbecco medium.

Cells were fused by treating almost confluent monolayers with $40 \%(w / w)$ polyethylene glycol (MW 1540, Koch Light) for about $2 \mathrm{~min}$ at room temperature followed by careful washing in medium and incubation at $37^{\circ} \mathrm{C}$ for about $4 \mathrm{~h}$. The homokaryons were trypsinized and transferred to HEPES-buffered medium. Small homokaryons (about 5 nuclei) were selected for the electrophysiological measurements of gap junction formation.

Spheroid growth was started from monolayer cells cultured on petri dishes (untreated for bacteriology; Greiner) where interconnected cells could be detached without the use of trypsin simply by gently agitating the medium. These cells proliferated and formed spheroids when transferred to the spinner flasks with daily medium change and harvesting for up to 9 days.

\section{Electron microscopy}

Spheroids were washed twice in phosphate buffered solution, fixed with $2.5 \%$ glutaraldehyde in phosphate buffered solution for $1 \mathrm{~h}$ at room temperature and stored at $4^{\circ} \mathrm{C}$ before they were rapidly frozen in liquid freon and freeze fractured in a Balzers BAF 301 instrument. Membranes were replicated by shadowing with Pt-C using an angle of about $45^{\circ}$ and stabilizing with a C-Film. Electron micrographs were taken with a Zeiss EM 10 microscope.

\section{Electrophysiology}

Electrical coupling was measured with high-impedance preamplifiers (WPI M 701 or $\mathrm{M} 750$ ) and $3 \mathrm{M} \mathrm{KCl}$ filled glass electrodes (Hilgenberg-Glas with inner 
filament) which had tip potentials $<-5 \mathrm{mV}$ and resistances of about $20 \mathrm{M} \Omega$. The coupling capacity of the cells was determined by different methods: Current injection in a cell and registration of the resulting hyper- or depolarizing potential changes in the same and in attached cells; measurement of the input resistance of the cells; iontophoresis of the fluorescent dye Lucifer yellow into one cell and observation of the spreading of the dye into the coupled cells. The opening of gap junction pores at first cell contact between homokaryons has been followed by a high resolution method (Loewenstein et al. 1978), using a Lock-in amplifier (Ithaco, Mod. 393). These measurements were performed with Leitz or Märzhäuser micromanipulators under a Zeiss Standard 14 microscope equipped with differential interference contrast, phase contrast and fluorescence optics.

\section{Results and Discussion}

Cells in a multicell spheroid may be subject to a limited endogenous regulation with respect to radiosensitivity and intercellular communication. The coupled BICR/M1R-K cells are more radioresistant when grown as spheroids than as monolayers. Since coupled cells are more radioresistant than uncoupled cells (Dertinger and Hülser 1981) the monolayer cells of BICR/M1R-K, therefore, should be less coupled than their counterparts in a spheroid. As can be seen from Fig. 1 the contrary is the case: the electrical coupling between cells in a spheroid decreases continuously until complete uncoupling occurs after $6-9$ days. This is rather the result of a simultaneous reduction of the inner diameter of all gap

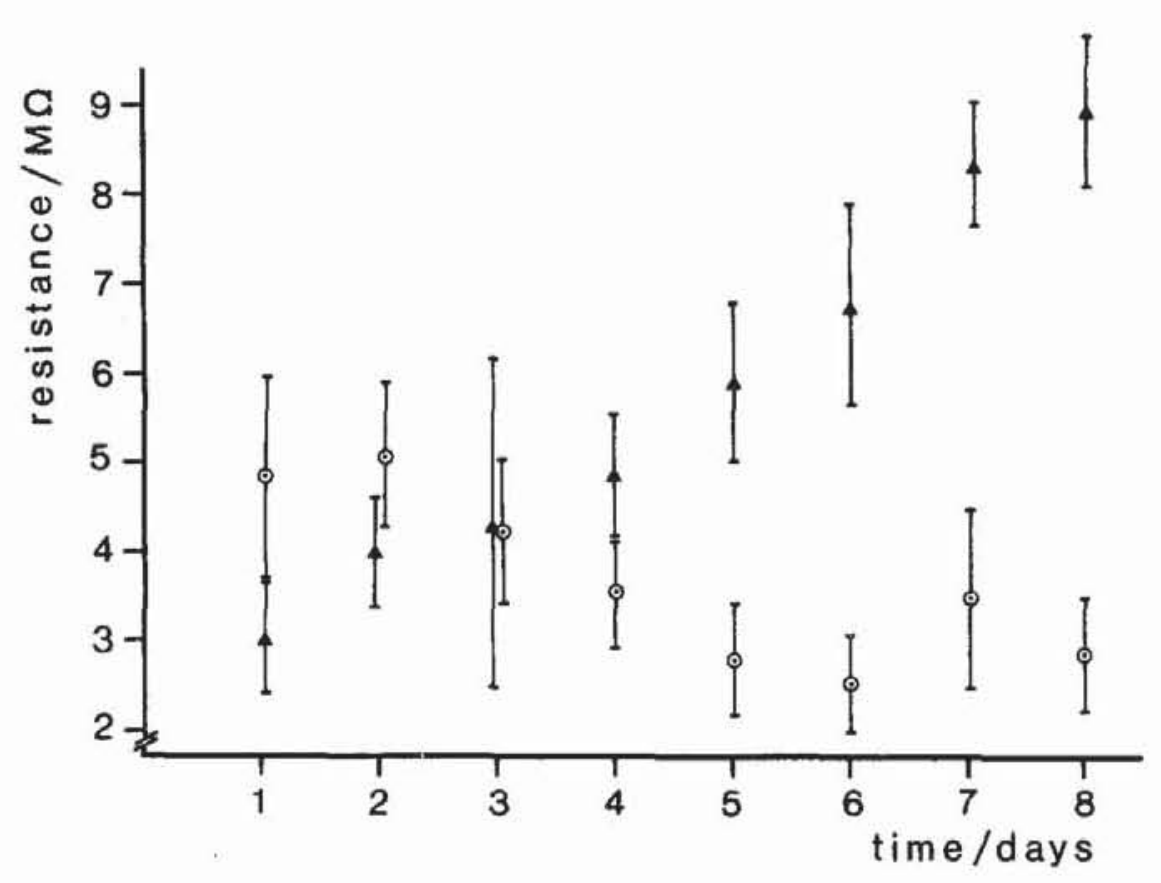

Fig. 1. The input resistance of cells in growing spheroids increases with time, indicating a decrease in junctional coupling, $(\mathbf{\Delta})$. Mean $\pm \mathrm{SD}, n \approx 235$. The input resistance of cells in a monolayer decreases with increasing cell density as more cells couple to each other, $(0)$. Mean $\pm \mathrm{SD}, n \approx 40$ 

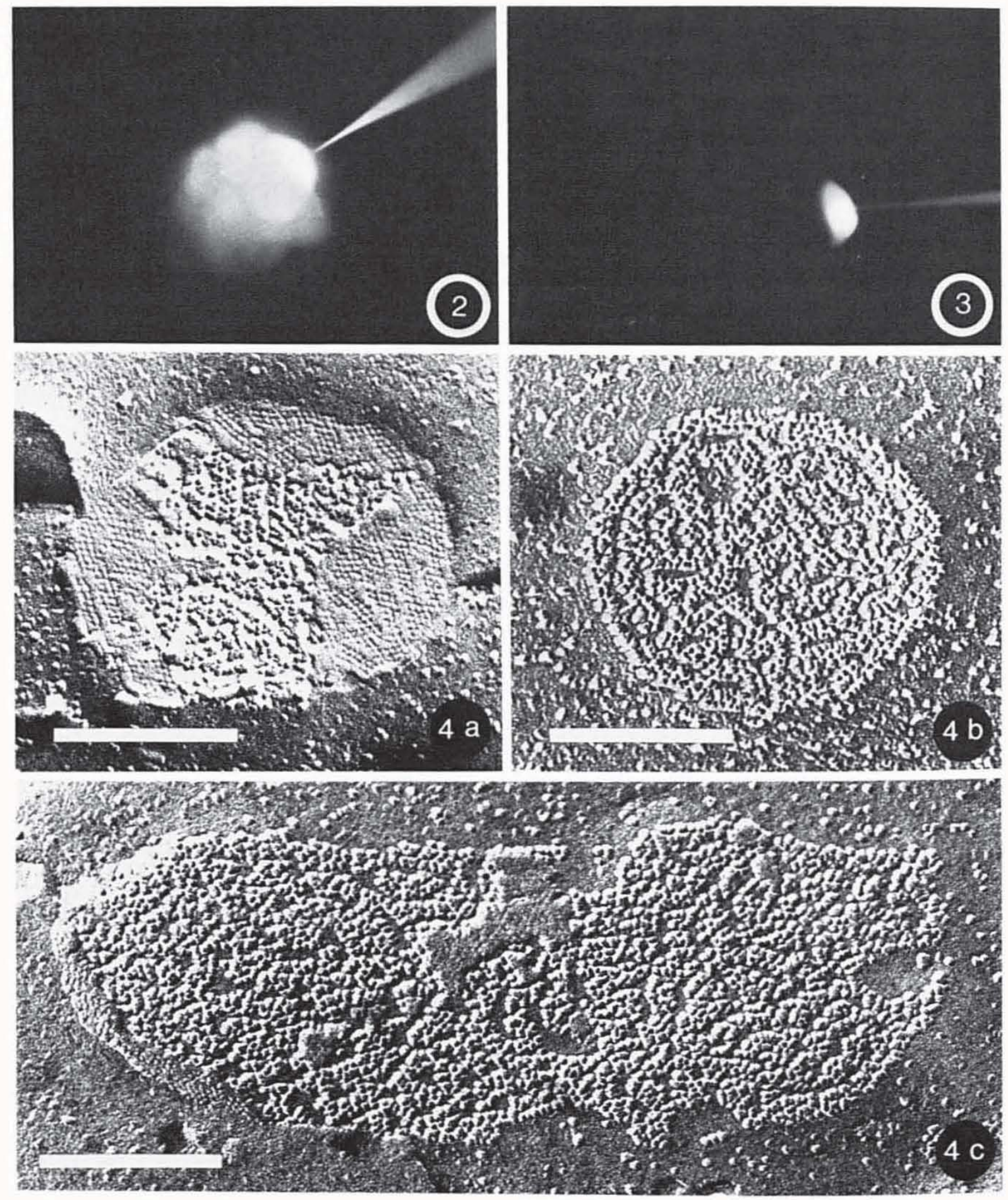

Fig. 2. Microiontophoresis of Lucifer yellow into a BICR/M1R-K cell of a 2 days old spheroid 4 min after injection of a $30 \mathrm{~s}, 10 \mathrm{nA}$ current pulse

Fig. 3. Microiontophoresis of Lucifer yellow into a BICR/M1R-K cell of a 4 days old spheroid 4 min after injection of a $30 \mathrm{~s}, 10 \mathrm{nA}$ current pulse

Fig. 4a-c. Gap junctions between BICR/M1R-K cells forming multicell spheroids. a A 2 days old spheroid; gap junctions are permeable for Lucifer yellow. b A 4 days old spheroid; gap junctions are only permeable for ionic current. c A 9 days old spheroid; gap junctions are completely closed. Bar: $0.2 \mu \mathrm{m}$ 
junction channels than of a complete closure of all pores in distinct gap junction plaques as demonstrated by iontophoresis of Lucifer yellow. This fluorescent dye spreads between cells of a 2 days old spheroid (Fig. 2) whereas 2 days later the dye is retained in the injected cell (Fig. 3). Interestingly, the proportion of gap junction plaques found between cells of spheroids did not vary with the age or size of spheroids (Figs, 4a and b) and gap junctions were also present in 9 days old spheroids, which are completely uncoupled (Fig. 4c). These experiments demonstrate that in a regulating system the existence of ionic or metabolic coupling cannot necessarily be deduced from the morphological existence of gap junctions.

Gap junctions may close all their pores without disassembling these plaques and the pores can be reopened. Our preliminary experiments, using $200 \mathrm{rad}$ $\mathrm{X}$-rays (Siemens Gammatron), revealed a recoupling of the BICR/M1R-K cells in spheroids within $6-8 \mathrm{~h}$ after irradiation.

The question whether a gap junction opens its pores gradually or in a single step can only be answered with confidence when just a few pores are involved in the measurement, i.e., when a gap junction is formed between cells contacting each other for the first time. A gradual opening should lead to a gradual increase of the transmitted signal in the cell which couples to the one the electrical signal is applied to. In the other case a stepwise increase with equal quanta of the transmitted signal should be recorded, every step representing the complete opening of a pore, i.e., a stepwise increase in junctional conductivity. In order to obtain stable measurements these experiments were performed with homokaryons. The transmitted signal was detected by its amplitude and phase with a Lock-in amplifier, which was automatically tuned to the signal amplitude of about $17 \mathrm{~Hz}$. The time between mechanical contact and onset of electrical coupling varied with temperature between 1 and $16 \mathrm{~min}$. In contrast to the experiment of Loewenstein et al. (1978) using Xenopus embryos, no quantal increase of the signal amplitudes during the coupling of BICR/M1R-K homokaryons was resolved. Within the first minute of gap junction pore formation the signal amplitude increased by $1.17 \pm 0.07 \mu \mathrm{V}$, within the third minute this increment of coupling increased to $3.61 \pm 0.30 \mu \mathrm{V}$.

Our results support the belief that gap junctions between BICR/M1R-K cells in a spheroid gradually reduce their pore diameter when an endogenously regulated uncoupling occurs. Opening of the gap junction pores at first cell contact is probably also a gradual process.

Acknowledgements. We thank U. Lauterwasser and H. Multhaupt for expert technical assistence.

This investigation was supported by the Deutsche Forschungsgemeinschaft.

\section{References}

Bennett MVL, Spray DC, Harris AL (1981) Gap junctions and development. Trends Neuro Sci $4: 159-163$

Dertinger H, Hülser D (1981) Increased radioresistance of cells in cultured multicell spheroids. I. Dependence on cellular interaction. Radiat Environ Biophys 19:101-107 
Flagg-Newton J, Simpson I, Loewenstein WR (1979) Permeability of the cell-to-cell membrane channels in mammalian cell junction. Science 205:404-407

Frank W, Ristow H-J, Schwalb S (1972) Untersuchungen zur wachstumsstimulierenden Wirkung von Kälberserum auf Kulturen embryonaler Rattenzellen. Exp Cell Res 70:390-396

Hülser DF, Webb DJ (1973) Relation between ionic coupling and morphology of established cells in culture. Exp Cell Res $80: 210-222$

Hülser DF, Lauterwasser U (1982) Membrane potential oscillations in homokaryons. Exp Cell Res 139: $63-70$

Ito S, Ikematsu Y (1980) Inter and intratissue communication during amphibian development. Dev Growth Differ 22:247-256

Lo CW, Gilula NB (1979a) Gap junctional communication in the preimplantation mouse embryo. Cell 18: 399-409

Lo CW, Gilula NB (1979b) Gap junctional communication in the post-implantation mouse embryo. Cell 18: 411-422

Loewenstein WR (1979) Junctional intercellular communication and the control of growth. Biochim Biophys Acta 560: 1-65

Loewenstein WR, Kanno Y, Socolar SJ (1978) The cell-to-cell-channel. Fed Proc $37: 2645-2650$

Schaller HC, Bodenmüller H (1981) Morphogene Substanzen aus Hydra. Naturwissenschaften $68: 252-256$

Weir MP, Lo CW (1982) Gap junctional communication compartments in the Drosophila wing disk. Proc Natl Acad Sci USA 79:3232-3235

Accepted October 8, 1982 